\title{
Comparing Effectiveness of Letrozole Versus Clomiphene Citrate to Evaluate the Ovulation Induction in patients with Polycystic Ovarian Syndrome
}

\author{
TEHMINA ZAFAR, FIZA ASIF, RUBINA NAURIN, TAYYABA MAJEED, ZAHID MAHMOOD \\ Department of Obstetrics and Gynaecology, Central Park Medical College, Lahore \\ Correspondence to Prof. Tayyaba Majeed, Email: dr.tayyaba@hotmail.com, Cell: 0300-4315535
}

\begin{abstract}
Background: Anovulation is the commonest cause of female infertility and polycystic ovarian syndrome (PCOS) is the most frequently seen cause of anovulation among infertile females. Letrozole and Clomiphene Citrate are two common drugs for PCOS. But controversial data was noticed regarding their effectiveness.

Aim: To compare effectiveness of Letrozole versus Clomiphene Citrate to evaluate the ovulation induction in patients with polycystic ovarian syndrome

Methods: After fulfilling the selection criteria, total 360 females were enrolled according to calculated sample size and were randomly divided into two equal groups. One is treated with letrozole and other is clomiphene citrate. Successful ovulation was noted on follow up. Data was collected in proforma and later on analyzed in SPSS version 23.

Results: The mean age of patients in letrozole group was $26.61 \pm 4.81$ years and in clomiphene citrate was it $27.89 \pm 4.24$ years. Successful ovulation induction was noted in 172 with letrozole and 150 with clomiphene citrate i. e p-value=0.001.

Conclusion: Letrozole has significantly better efficacy for successful ovulation than Clomiphene Citrate for PCOS.

Keywords: Ovulation, Clomiphene citrate, Letrozole, polycystic ovarian syndrome
\end{abstract}

\section{INTRODUCTION}

Infertility affects $10-15 \%$ of the married couples and is a cause of great concern for these couples. Etiologies of infertility can, broadly, be divided into male and female factors ${ }^{1}$. Anovulation is the commonest cause of female infertility and polycystic ovarian syndrome (PCOS) is the most frequently seen cause of anovulation among infertile females ${ }^{2}$. A clinical diagnosis of PCOS can easily be made using Rotterdam Criteria ${ }^{3}$. Infertile females suffering from PCOS often need ovulation induction to achieve conception and there are some options available with variable results. The frequency of PCOS is determined by the diagnostic criteria used. According to the World Health Organization, it affects 116 million women worldwide as of 2010 (about $3.4 \%$ females) ${ }^{4}$. According to a community-based prevalence survey using the Rotterdam criterion, approximately $18 \%$ of women have PCOS, with $70 \%$ of them previously undiagnosed $d^{4,5}$.

Since its introduction in 1956, Clomiphene Citrate, a nonsteroidal selective estrogen receptor modulator, has been the first line drug for ovulation induction in females with $\mathrm{PCOS}^{2}$. Clomiphene Citrate has a high ovulation induction rate $(60-85 \%)$ but comparatively low pregnancy rate $(10-20 \%)$, with a higher miscarriage rate $(20-25 \%)^{6}$. Tamoxifen is another anti-estrogen used for ovulation induction, with no evidence of success over Clomiphene Citrate, in terms of ovulation or pregnancy rates ${ }^{2}$.

Letrozole, an aromatase inhibitor and originally used for chemotherapy in breast cancer, was proposed for ovulation induction, in the year 2000, by Robert Casper and Mohamed F.M. Mitwally. Letrozole inhibits the conversion of androgens to estradiol thus increasing FSH level and also increases FSH receptors in ovarian tissue ${ }^{8}$. It has a short half-life ( $\left.45 \mathrm{hrs}\right)$ and it does not cause down regulation of estrogen receptors ${ }^{9}$.

The data available from studies conducted in Pakistan and neighbouring countries, comparing the efficacy of Clomiphene Citrate and Letrozole, are inconclusive. Irum Mobusher from Pakistan and Sujata Kar from India showed almost similar and statistically insignificant results for ovulation rate, endometrial thickness but statistically significant pregnancy rate $(p=0.0125)^{6,10}$. Fauzia Haq Nawaz demonstrated no statistical difference between the two drugs in terms of endometrial thickness and pregnancy rate ( $p=0.67 \& p=0.9$ respectively) ${ }^{11}$. However, Roy et al, in their study Letrozole to have statistically better results in terms of endometrial thickness and pregnancy rates $(p=0.014 \& p=0.041$ respectively) when compared to Clomiphene Citrate ${ }^{12}$.

Received on 17-05-2021

Accepted on 27-09-2021
Similarly, Azra Azmoodeh and associates demonstrated higher ovulation and pregnancy rates when treated with Letrozole ${ }^{8}$. This study is being conducted to find out if Letrozole is actually superior to Clomiphene Citrate, to propose and help establish local guideline for ovulation induction, in infertile females suffering from PCOS.

The objective of the study was to compare effectiveness of Letrozole and Clomiphene Citrate (CC), for ovulation induction in patients with PCOS

\section{PATIENTS AND METHODS}

This randomized controlled trial was conducted in Infertility clinic, Rashid Latif Medical College Lahore for a period of 6 months from 1-3-2017 to 1-9-2017 after permission from IRB. Sampling technique used was non probability consecutive sampling.

Sample size: Taking the successful ovulation induction rate of $60.78 \%$ to Clomiphene Citrate $(P 1)$ and $73.08 \%$ to Letrozole $(P 2)^{6}$, and $05 \%$ level of significance and $80 \%$ power of test, a sample size of 180 patients per group has beencalculated.

Inclusion Criteria: All infertile females presenting to infertility clinic with c/o failure to achieve a pregnancy after 12 months or more of regular unprotected sexual intercourse. All infertile female patients with established diagnosis of PCOS (Rotterdam Criteria) as the cause of infertility were included with two of the following three criteria:

- Oligo/anovulation i.e. less than 6-9 cycles per year.

- Hyperandrogenism: clinical (hirsutism(Ferriman-Gallwey

score $>8$ ) or less commonly male pattern alopecia) or biochemical (raised FAl or free testosterone)

- Polycystic ovaries on ultrasound i.e. $\geq 12$ Antral follicles in one ovary or ovarian volume $\geq 10 \mathrm{~cm}^{3}$.

Exclusion Criteria: Females from couples with male factor infertility, endometriosis, tubal, uterine and/or cervical pathology as the cause of infertility, diagnosed endocrine disorder, taken any treatment for infertility previously.

Data collection: 250 infertile females with established diagnosis of anovulation as the cause of infertility, who fulfilled the inclusion and exclusion criteria, was enrolled to the study. All of the study participants were provided details about the conduct of the study, including the details of the drugs under study and randomization process. They were also informed about their right to withdraw from study, at any time, without having any fear of refusal of treatment. A written informed consent was obtained from eachstudy participant, mentioning their willingness to participate in the study and for use of their data for study and publication. Demographic information 
i.e. age, education, and duration of infertility was collected. Each participant inquired about the duration and regularity of her menstrual cycle. The study group was assigned to the participant by using random number table. Patients in Group 1 received Letrozole $2.5 \mathrm{mg}$ per day (oral), from day 2 to day 6 of their menstrual cycle. Patients in 2 group received Clomiphene Citrate $50 \mathrm{mg}$ per day (oral) from day 2 to day 6 of the cycle. All the patients, in both groups, were evaluated for ovulation, number and size of ovarian follicle and endometrial thickness through TVS done by a single consultant sinologist (to avoid discrepancy of measurements due to individual skills). Patients in both groups were treated and assessed for outcome variables i.e. follicular development and endometrial thickness, for one menstrual cycle only. Effectiveness was measured in terms successful ovulation induction i.e. follicular development and endometrial thickness. During one cycle only. Successful ovulation induction, assessed by at least one ovarian follicle with the size $\geq 18 \mathrm{~mm}$ is found, on TVS, from day 12 to day 18 of the cycle and Endometrial thickness of $6 \mathrm{~mm}$ or more with trilaminar pattern. All the participants were provided further treatment as per standard operating procedures of the institute. All this information collected on Performa.

Data analysis: All the data collected was analyzed using SPSS version 23. Descriptive Statistics was calculated. Quantitative data like pattern of duration of infertility. Qualitative data like pattern of menstrual cycle in term of (2-5, 6-10>11 years) and effectiveness successful ovulation induction will be presented as frequencies and percentages. Age and endometrial thickness was presented as mean and standard deviation.

\section{RESULTS}

The mean age of the patients in letrozole group was $26.61 \pm 4.81$ years and in clomiphene citrate was $27.89 \pm 4.24$ years. The mean duration of infertility in letrozole group was $4.11 \pm 3.50$ years and in clomiphene citrate was $4.70 \pm 3.404$ years. The regular pattern of menstrual cycle was found in 179 cases in which 96 were from letrozole group and 83 were from clomiphene citrate group, similarly the irregular pattern was found in 181 cases in which 84 were from letrozole group and 7 were from clomiphene citrate group. In our study the monofillicles were noted in 176 cases in which 95 were from letrozole group and 81 were from clomiphene citrate group, similarly the multi-follicular patients were 184 in which 85 were from letrozole group and 99 were from clomiphene citrate group (Table 1).

The mean ET at day 12 in letrozole group was $4.72 \pm 0.95$ and in clomiphene citrate group was $4.42 \pm 0.99$. The mean ET at day 14 in letrozole group was $6.10 \pm 1.210$ and in clomiphene citrate group was $5.67 \pm 1.17$. The mean ET at day 16 in letrozole group

In this study, successful ovulation induction was noted in $322(89.44 \%)$ patients and unsuccessful ovulation induction was found in $38(10.56 \%)$ patients (Fig 1).

In our study the successful ovulation induction was found in 322 cases in which 172 were randomized to letrozole group and 150 were randomized to clomiphene citrate group, similarly the unsuccessful ovulation induction was noted in 38 cases in which 8 females had letrozole and 30 females had clomiphene citrate. Statistically, the difference was significant in both groups for ovulation induction i.e. $p$-value $=0.001$ (Table 3 ). In patients with age $\leq 30$ years, the successful ovulation induction was noted in 226 patients in which 126 were from letrozole group and 100 were from clomiphene citrate group, similarly in patients with age $>30$ years the successful ovulation induction was noted in 96 cases in which 46 were from letrozole group and 50 were from clomiphene group. Statistically, the difference was significant i.e. $p$-value $<0.05$. In patients with duration of infertility $\leq 10$ years, the successful ovulation induction was noted in 297 patients in which 158 were from letrozole group and 139 were from clomiphene citrate group, was $7.29 \pm 1.310$ and in clomiphene citrate group was $6.62 \pm 1.469$. In this study the mean ET at day 18 in letrozole group was $8.09 \pm 1.405$ and in clomiphene citrate group was 7.28 \pm 1.427 . Statistically, the difference was significant in both groups i.e. pvalue $<0.05$ on each visit (Table 2 ).

Table 1: Demographics of females

\begin{tabular}{|l|c|c|}
\hline \multirow{2}{*}{} & \multicolumn{2}{|c|}{ Study groups } \\
\cline { 2 - 3 } & Letrozole & Clomiphene citrate \\
\hline $\mathbf{n}$ & $\mathbf{1 8 0}$ & $\mathbf{1 8 0}$ \\
\hline Age (years) & $26.61 \pm 4.81$ & $27.89 \pm 4.24$ \\
\hline Duration of infertility & $4.11 \pm 3.50$ & $4.70 \pm 3.40$ \\
\hline Pattern of menstrual cycle & \multicolumn{2}{|}{} \\
\hline Regular & 96 & 83 \\
\hline Irregular & 84 & 97 \\
\hline No. of follicles & \multicolumn{2}{|}{} \\
\hline Monofollicular & 95 & 81 \\
\hline Multi-follicular & 85 & 99 \\
\hline
\end{tabular}

Table 2: Comparison of endometrial thickness at day 12 with study groups

\begin{tabular}{|l|c|c|c|}
\hline \multirow{2}{*}{$\begin{array}{l}\text { Endometrial } \\
\text { thickness(cm) }\end{array}$} & \multicolumn{2}{|c|}{ Study Groups } & P value \\
\cline { 2 - 4 } & Letrozole & Clomiphene citrate & \\
\hline Day 12 & $\mathbf{1 8 0}$ & $\mathbf{1 8 0}$ & \\
\hline Day 14 & $4.72 \pm 0.95$ & $4.42 \pm 0.99$ & 0.004 \\
\hline Day 16 & $6.10 \pm 1.21$ & $5.67 \pm 1.17$ & 0.01 \\
\hline Day 18 & $7.29 \pm 1.31$ & $6.62 \pm 1.47$ & 0.001 \\
\hline
\end{tabular}

Fig 1: Frequency distribution of ovulation induction

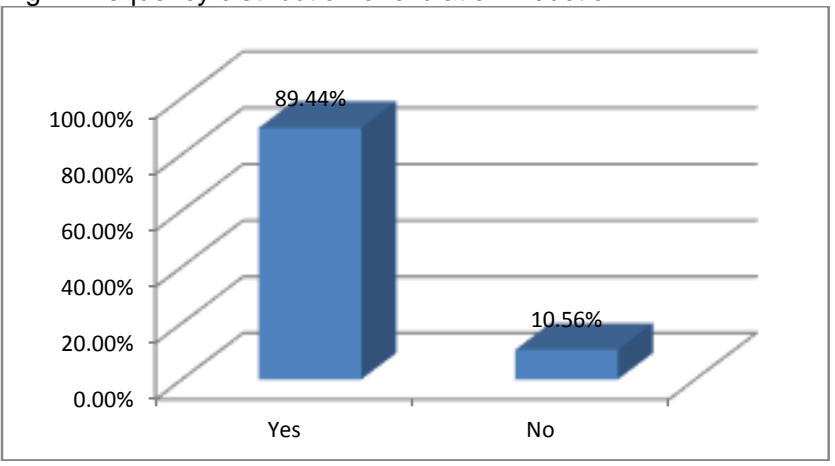

Table 3: Comparison of ovulation induction in both groups

\begin{tabular}{|l|c|c|c|}
\hline $\begin{array}{l}\text { Ovulation } \\
\text { induction }\end{array}$ & \multicolumn{2}{|c|}{ Study Groups } & \multirow{2}{*}{ Total } \\
\cline { 2 - 3 } & Letrozole & Clomiphene citrate & \\
\hline Yes & 172 & 150 & 322 \\
\hline No & 8 & 30 & 38 \\
\hline Total & $\mathbf{1 8 0}$ & $\mathbf{1 8 0}$ & 360 \\
\hline
\end{tabular}

Similarly in patients with duration of infertility $>10$ years the successful ovulation induction was noted in 25 cases in which 14 were from letrozole group and 11 were from clomiphene group. Statistically, the difference was significant i.e. $p$-value $=0.001$. In patients with regular pattern of menstrual cycle, the successful ovulation induction was noted in 157 patients in which 90 were from letrozole group and 67 were from clomiphene citrate group, similarly in patients with irregular pattern of menstrual cycle the successful ovulation induction was noted in 165 cases in which 82 were from letrozole group and 83 were from clomiphene group. Statistically, the difference was significant i.e. $p$-value $<0.05$. In patients with mon-follicular, the successful ovulation induction was noted in 163 patients in which 92 were from letrozole group and 71 were from clomiphene citrate group, similarly in patients with multiple-follicular, the successful ovulation induction was noted in 159 cases in which 80 were from letrozole group and 79 were from clomiphene group. Statistically, the difference was significant in both groups i.e. $p$-value $=<0.05$. (Table 4). 
Table 4: Comparison of ovulation induction with study groups stratified for effect modifiers

\begin{tabular}{|c|c|c|c|c|c|}
\hline \multirow[t]{2}{*}{ Age (years) } & \multirow{2}{*}{$\begin{array}{l}\text { Ovulation } \\
\text { induction }\end{array}$} & \multicolumn{2}{|c|}{ Study Groups } & \multirow[t]{2}{*}{ Total } & \multirow[t]{2}{*}{ p-value } \\
\hline & & Letrozole & Clomiphene citrate & & \\
\hline \multirow[t]{2}{*}{$\leq 30$} & Yes & 126 & 100 & 226 & \multirow[t]{2}{*}{0.007} \\
\hline & No & 8 & 20 & 28 & \\
\hline \multirow[t]{2}{*}{$>30$} & Yes & 46 & 50 & 96 & \multirow[t]{2}{*}{0.005} \\
\hline & No & 0 & 10 & 10 & \\
\hline \multicolumn{6}{|c|}{ Duration of infertility } \\
\hline \multirow[t]{2}{*}{$\leq 10$} & Yes & 158 & 139 & 297 & \multirow[t]{2}{*}{0.001} \\
\hline & No & 8 & 27 & 35 & \\
\hline \multirow[t]{2}{*}{$>10$} & Yes & 14 & 11 & 25 & \multirow[t]{2}{*}{0.222} \\
\hline & No & 0 & 3 & 3 & \\
\hline \multicolumn{6}{|c|}{ Pattern of menstrual cycle } \\
\hline \multirow[t]{2}{*}{ Regular } & Yes & 90 & 67 & 157 & \multirow[t]{2}{*}{0.008} \\
\hline & No & 6 & 16 & 22 & \\
\hline \multirow[t]{2}{*}{ Irregular } & Yes & 82 & 83 & 165 & \multirow[t]{2}{*}{0.007} \\
\hline & No & 2 & 14 & 16 & \\
\hline \multirow{3}{*}{\begin{tabular}{l|} 
No. of follicles \\
Mono-follicular
\end{tabular}} & & & & & \\
\hline & Yes & 92 & 71 & 163 & \multirow[t]{2}{*}{0.039} \\
\hline & No & 3 & 10 & 13 & \\
\hline \multirow[t]{2}{*}{ Mutiple-follicular } & Yes & 80 & 79 & 159 & \multirow[t]{2}{*}{0.005} \\
\hline & No & 5 & 20 & 25 & \\
\hline
\end{tabular}

\section{DISCUSSION}

One of the most common causes of reproductive failure in infertile couples is ovarian dysfunction. Infertile people have a $30 \%$ to $40 \%$ chance of developing this condition. PCOS is a common condition that is linked to ovulation deficiency and affects $7 \%$ of women of childbearing age. Clomiphene citrate is the most commonly prescribed oral ovulation inducer. Letrozole is a nonsteroidal aromatase inhibitor that was initially used to treat postmenopausal breast cancer and is currently the only permitted indication ${ }^{13,14}$

In our study the successful ovulation induction was noted in 322 cases in which 172 were from letrozole group and 150 were from clomiphene citrate group. Statistically, significant difference has been observed in both groups for ovulation induction ( $p$ value $=0.001$ ). In our study significantly higher ET value was noted in letrozol group than to Clomiphene Citrate group. A study by Mobusher et al., ${ }^{15}$ documented a higher rate of mono-follicular development and conception when letrozole was given for ovulation induction in females with complaint of infertility due to PCOS, which was statistically significant $(p<0.05)$. Letrozole was reported to be significantly better for ovulation induction in females who were resistant to the Clomiphene Citrate. Hyperinsulinemia, which is significantly related to the PCOS, is considered as the major contributory risk factor for resistance against Clomiphene Citrate $^{16}$.

Roy et al, in their study Letrozole to have statistically better results in terms of endometrial thickness and pregnancy rates ( $p=0.014 \& p=0.041$ respectively) when compared to Clomiphene Citrate $^{12}$. Azra Azmoodeh and associates demonstrated higher ovulation and pregnancy rates when treated with Letrozole ${ }^{8}$. Badawy et al., recorded statistically slightly higher endometrial thickness in the Clomiphene Citrate group (9.20.7) vs. letrozole (8.10.2, $\mathrm{P}=0.021)$ in their sample of 438 patients with 1063 cycles, one of the largest trials comparing Clomiphene Citrate and letrozole. ${ }^{17} \mathrm{Few}$ trials have shown a substantial variation in endometrium effects between the two classes ${ }^{18,19}$.

Banerjee et al., compared letrozole $(2.5 \mathrm{mg})$ to clomiphene in 147 Indian women with PCOS in a recent report $(100 \mathrm{mg})$. The mean endometrial growth in the letrozole community was $8.7211 .41 \mathrm{~mm}$, whereas it was $8.781 .16 \mathrm{~mm}$ in the Clomiphene Citrate group $(P=0.004)^{18}$. Letrozole was linked to increased endometrial thickness, according to Mitwally and Casper ${ }^{20}$. According to a study conducted by $\mathrm{Xi}$ et al., Letrozole combined with $\mathrm{HMG}$ is an important protocol for minimizing the chances of hyperstimulation for ovarian induction in Clomiphene Citrateresistant women with PCOS. In patients that are especially vulnerable to gonadotropin, this formulation could be more suitable ${ }^{21}$.

The mean endometrial growth was $8.721 .41 \mathrm{~mm}$ in the letrozole group and $8.781 .16 \mathrm{~mm}$ in the clomiphene group $(P=0.004)$, according to an analysis by Banerjee et al. Letrozole has a positive effect on the endometrium, theoretically increasing pregnancy rates in women with PCOS following successful ovulation induction. ${ }^{18}$ In a meta- analysis by $\mathrm{He} \&$ Jiang, the therapeutic effectiveness of letrozole for ovulation induction in PCOS women was linked to clomiphene. This is one of the most comprehensive meta-analyses of the topic ever written ${ }^{22}$.

Six randomized trials with a total of 841 patients were examined. There were no major variations between the two classes in terms of fertility rates, abortion rates, or multiple birth rates. Irum Mobusher from Pakistan and Sujata Kar from India had nearly identical and statistically negligible ovulation and endometrial thickness outcomes, but a statistically important pregnancy rate $(p-$ value $=0.0125)^{6,10}$. In terms of endometrial thickness and conception incidence, Fauzia Haqnawaz found no statistical discrepancy between the two treatments $(p \text {-value }>0.05)^{11}$.

Infertility is one of the common problems that face women with PCOS and the FSH and Clomiphene Citrate are the principal treatments used for anovulating women. Gonadotropins are used to induce ovulation in women with PCOS who do not respond to Clomiphene Citrate. Also lowering insulin levels by using insulinsensitising drugs such as biguanides and thiazolidinediones may restore fertility. The laparoscopic ovarian surgery "ovarian drilling" is used to induce ovulation in Clomiphene Citrate resistance women with anovulatory PCOS. Other option for achieving pregnancy in women with PCOS is to use in Vitro Fertilization ${ }^{23}$

\section{CONCLUSION}

Our study proved that Letrozole group showed significantly better efficacy in terms of ET and successful ovulation induction than to Clomiphene Citrate group in patients with PCOS.

\section{REFERENCES}

1. Angel M, Ghose S, Gowda M. A randomized trial comparing the ovulation induction efficacy of clomiphene citrate and letrozole. J Nat Sci Biol Med 2014 Jul;5(2):450-2.

2. Seyedoshohadaei $F$, Zandvakily $F$, Shahgeibi S. Comparison of the effectiveness of clomiphene citrate, tamoxifen and letrozole in ovulation induction in infertility due to isolated unovulation. Iranian journal of reproductive medicine 2012 Nov;10(6):531-6.

3. Boyle J, Teede H. Polycystic ovary syndrome An update. Australian Family Physician 2012 10/01;41:752-6.

4. Vos $T$, Flaxman $A D$, Naghavi M, Lozano $R$, Michaud $C$, Ezzati M, et al. Years lived with disability (YLDs) for 1160 sequelae of 289 diseases and injuries 1990-2010: a 
systematic analysis for the Global Burden of Disease Study 2010. The Lancet 2013;380(9859):2163-96.

5. Teede H, Deeks A, Moran L. Polycystic ovary syndrome: a complex condition with psychological, reproductive and metabolic manifestations that impacts on health across the lifespan. BMC medicine 2010;8(1):41.

6. Kar S. Clomiphene citrate or letrozole as first-line ovulation induction drug in infertile PCOS women: A prospective randomized trial. J Hum Reprod Sci 2012 Sep;5(3):262-5.

7. Kar S. Current evidence supporting "letrozole" for ovulation induction. J Hum Reprod Sci 2013 Apr;6(2):93-8.

8. Azmoodeh A, Pejman Manesh M, Akbari Asbagh $F$, Ghaseminejad A, Hamzehgardeshi Z. Effects of LetrozoleHMG and Clomiphene-HMG on Incidence of Luteinized Unruptured Follicle Syndrome in Infertile Women Undergoing Induction Ovulation and Intrauterine Insemination: A Randomised Trial. Glob J Health Sci 2015;8(4):45762.

9. Palihawadana TS, Wijesinghe PS, Seneviratne HR. Factors associated with nonresponse to ovulation induction using letrozole among women with World Health Organization group II anovulation. J Hum Reprod Sci 2015 Apr-Jun;8(2):759.

10. Mobusher I. Comparison of the Efficacy of Letrozole and Clomiphene Citrate for Ovulation Induction in Infertile Women with Polycystic Ovary Syndrome. Pakistan Journal of Medical and Health Sciences [Original Article] 2014;8(4):4.

11. HaqNawaz F, Virk S, Qadir T, Imam S, Rizvi J. Comparison of Letrozole and Clomiphene Citrate Efficacy along with Gonadotrophins in Controlled Ovarian

12. Hyperstimulation for Intrauterine Insemination Cycles. Journal of Reproduction \& Infertility 2013;14(3):138-42.

13. Roy KK, Baruah J, Singla S, Sharma JB, Singh N, Jain SK, et al. A prospective randomized trial comparing the efficacy of Letrozole and Clomiphene citrate in induction of ovulation in polycystic ovarian syndrome. J Hum Reprod Sci 2012 Jan;5(1):20-5.

14. Nahid L, Sirous K. Comparison of the effects of letrozole and clomiphene citrate for ovulation induction in infertile women with polycystic ovary syndrome. Minerva ginecologica 2012;64(3):253-8.

15. Casper RF, Mitwally MF. Use of the aromatase inhibitor letrozole for ovulation induction in women with polycystic ovarian syndrome. Clinical obstetrics and gynecology 2011;54(4):685-95.

16. MOBUSHER I. Comparison of the efficacy of letrozole and clomiphene citrate for ovulation induction in infertile women with polycystic ovary syndrome. Age (years) 2014;24(2.33):24.9-2.31.

17. Ganesh A, Goswami SK, Chattopadhyay R, Chaudhury K, Chakravarty B. Comparison of letrozole with continuous gonadotropins and clomiphene-gonadotropin combination for ovulation induction in 1387 PCOS women after clomiphene citrate failure: a randomized prospective clinical trial. Journal of assisted reproduction and genetics 2009;26(1):19-24.

18. Badawy A, Aal IA, Abulatta M. Clomiphene citrate or letrozole for ovulation induction in women with polycystic ovarian syndrome: a prospective randomized trial. Fertility and sterility 2009;92(3):849-52

19. Ray PB, Ray A, Chakraborti P. Comparison of efficacy of letrozole and clomiphene citrate in ovulation induction in Indian women with polycystic ovarian syndrome. Archives of gynecology and obstetrics 2012;285(3):873-7.

20. Kilic-Okman T, Kucuk M, Altaner S. Comparison of the effects of letrozole and clomiphene citrate on ovarian follicles, endometrium, and hormone levels in the rat. Fertility and sterility 2003;80(6):1330-2.

21. Mitwally MF, Casper RF. Use of an aromatase inhibitor for induction of ovulation in patients with an inadequate response to clomiphene citrate. Fertility and sterility 2001;75(2):305-9.

22. Xi W, Liu S, Mao H, Yang Y, Xue X, Lu X. Use of letrozole and clomiphene citrate combined with gonadotropins in clomiphene-resistant infertile women with polycystic ovary syndrome: a prospective study. Drug design, development and therapy 2015;9:6001.

23. He D, Jiang F. Meta-analysis of letrozole versus clomiphene citrate in polycystic ovary syndrome. Reproductive biomedicine online 2011;23(1):91-6.

24. Al-Shaikh SF, Al-Mukhatar EJ, Al-Zubaidy AA, Al-Rubaie BJ, Al-Khuzaee L. Use of clomiphene or letrozole for treating women with polycystic ovary syndrome related subfertility in Hilla city. Middle East Fertility Society Journal 2017;22(2):105-10. 